Professor Ruzhi XU, PhD

College of Finance, Qilu University of Technology, Jinan, Shandong

Associate Professor Khalid KHAN, PhD (Corresponding author)

College of Finance, Qilu University of Technology, Jinan, Shandong

Email: Shah_khan884@yahoo.com

Professor Nicoleta - Claudia MOLDOVAN, PhD

West University of Timisoara

Associate Professor Anda IOSIF, PhD

West University of Timisoara

\title{
DO HOUSE PRICES AND MARRIAGES MOVE TOGETHER IN CHINA?
}

Abstract. This paper tests the duration model to evaluate the causality relationship between house prices $(H P)$ and marriages $(M R)$ in China. The results find that HP do Granger cause MR in Western regions and vice versa. In the other three regions the HP does not Granger cause the MR except for Beijing and Henan in the Eastern and Central regions respectively. The shortage in the land supply, higher income, and population in the Eastern region results in housing problems and increases the competition for MR. However, relaxed land supply and a low developmental level make real estate less attractive for investors but do not hinder MR in the Western region. Moreover, MR is leading HP in Jilin in the Northeastern region because of the gender imbalance and lowest fertility rate which increases the housing demand for MR. Our results conclude that HP influence MR positively which is contrary to the duration model, stating that rising HP will decrease the MR. The government should balance regional development, the housing market, and social coordination to minimize the rising $H P$ on the MR. As a result, it will prevent the MR from declining and will mitigate the sex-ratio imbalance as well as the housing market.

Keywords: House Prices; Marriage; Bootstrap Panel Causality test.

\section{JEL Classification : C10, R31, Z13}

\section{Introduction}

The importance of homeownership is undeniable in society (Zhang et al., 2018). It starts with marriage (MR), the social institution which offers benefits to society in the form of happiness, fertility and controls the crime rate. Both Eastern and Western societies believe that MR and house prices (HP) have a strong association and increasing tendency of HP push downwards MR (Farzanegan and Fereidouni, 2014).

DOI: 10.24818/18423264/53.4.19.04 
Information about housing has gotten immense importance for the financial market and policymakers since the financial crisis in 2008. HP and MR have a durable relationship as married people tend to own a house as compared to those who are unmarried. Therefore, a decline in MR will lower the demand for houses and will ultimately impact HP negatively. Moreover, the delayed MR and the falling home ownership have become the predominant phenomenon in many countries. The instability in HP has an important impact on the average age and timing for MR ( $\mathrm{Li}$, 2018). It is maintained that HP and MR have a two-way relationship. The rising trend of MR may increase the demand for new housing, will exert pressure on the HP and vice versa. Thus, the housing supply plays a crucial part in the MR frequency. The high HP can decrease the household spending and discouraging couples from entering a MR (Aksoy, 2016). It will increase the cost of living, financial stress and will diminish the chances of MR (Farnham et al., 2011). The soaring HP will push people to invest their money in acquiring a house, which might decrease the effective demand. Also, it can stimulate the real estate industry and intensify investment (Zhang et al., 2012). However, the rising HP trend may have negative effects on social stability and lead to a reduction in MR.

China has started the transition process to a market economy in 1978 (Wrenn et al., 2018). The housing sector is considered among the main pillars of economic growth and the safest way of investment for Chinese people. It provides huge revenues to local governments and accounts for $15 \%$ of the Gross Domestic Product (GDP). The welfare housing system was replaced with monetizing housing allocation ( $\mathrm{Li}$ and Song, 2016). The first step toward market-based housing was initiated when the state Council Document No.23 stopped the state-owned enterprises to provide public housing in 1998 (Wrenn et al., 2018). The period has witnessed social and demographic changes, especially the weakening of MR institution (Yu and Xie, 2015). As in the controlled economic system, housing for married couples was the responsibility of the government and it was not a criterion for the MR. While housing has become mandatory for the MR in the market-based economy and $70 \%$ of the women in China confirm housing a prerequisite for the MR. The MR without housing is considered "naked marriages" 1 " and the role of the "mother in law" economy is very important. High HP has a negative impact on MR (Wrenn et al., 2018). Therefore, the highest homeownership is recorded in China as a consequence of cultural desire and social standing. It is one of the prerequisites for MR which put pressure on the HP and move together (Wei et al., 2017). The one-child policy resulted in the skewed sexratios which affect the household saving while the homeownership increases the

\footnotetext{
${ }^{1}$ The type of MR when loving partner in young generation get married without any house, car and also no ceremony.

${ }^{2}$. The mother of the wives prefers man for their daughters who owns a housing, indicates the investing in housing and saving in the form of housing
} 
Do House Prices and Marriages Move Together in China?

marriageability chances (Wei and Zhang, 2011). According to Hongkong and Shanghai Banking Corporation (HSBC, 2018), more than $70 \%$ of the Chinese male aged (19-36) own housing which is double as compared to the U.S.

The housing market remained modest during 1998-2002, even the government dropping the interest rate to encourage the private sector. However, the MR declined consecutively for six years because of the various economic reforms and marketization of the housing system (Yu and Xie, 2015). The new law "Regulations on the Marriage Registration" was promulgated in October 2003 to safeguard the legitimate right and interest of couples. It facilitated the registration procedure which has resulted in the rise of MR. At this juncture, the housing sector started to boom in 2003 which lasted for the next decade. The government recognized the importance by issuing "Promoting Sustainable and Healthy Development of the Real Estate Market". The basic purpose of this policy was to withdraw government-sponsored housing from urban occupants and push them to buy housing in the private market. This has narrowed down the number of urban low-income beneficiaries which has increased the housing demand as well as HP (Li and Song, 2016). Similarly, it provides easy credit to the real estate industry and HP increased by $12.5 \%$ in 2004 . Meanwhile, MR has witnessed an increasing pattern and almost 8.86 million marriages were registered. However, the pace of the HP has slowed down by issuing "State 6 " regulations in 2006 aimed at provision of the subsidized housing for the low income. Both HP and MR witnessed an upward trend during 2003-2007 and Guangdong, Hebei, Henan, Jiangsu and Shandong recorded the highest MR. The HP witnessed a short rapid boom in 2007 driven by the deterioration of the Chinese manufacturing industry. The capital inflow increased in the real estate from the manufacturing industries due to the rising labor costs and interest rate. The government has initiated control over the HP by speculating investment through land supervision (Li and Song, 2016). The effectiveness of these policies was materialized and the HP was corrected around the financial crisis in 2008 which lasted for one year. However, a rapid HP is observed during 2009-2010 with an average 30\% increase in the major cities. As an important sector of the economy and to combat the financial crisis impacts on the real estate, the government provided the stimulus package in 2009 (Zhang et al., 2012).

While the above-mentioned policies resulted in higher housing speculation, regulation was established in 2010. A new round of policies "State $11^{4}$ " was introduced to tackle speculation and made the local governments' responsibility to supply affordable housing and reduce credit risk. The "social security housing" project

\footnotetext{
${ }^{3}$ The basic purpose of the policy to regulate the housing supply mechanism as well as reinforce the government contribution in the taxation, credit and land policy.

${ }^{4}$ The policy has mandated the local governments to provide the affordable housing supply besides curbing the speculation and minimize the credit risk.
}

DOI: 10.24818/18423264/53.4.19.04 
was introduced in 2009 with the objective of discounting the price for low-income families. The HP peaked again in the first quarter of 2010 with an increase of $32.9 \%$. On the other side, the MR observed an increasing movement with an average rise of $1.8 \%$. Accordingly, an increase in MR generates continuous growth in housing demand and expected a positive effect on the housing affordability. The government intervened to regulate the soaring price with "New State 8 ", regulation which aims to respond to the provinces' need to introduce more strict policies to control the HP. It has increased the down payment from $50 \%$ to $60 \%$ on buying a second house ( $\mathrm{Li}$ and Song, 2016). During 2003-2013 the HP increased five-fold and observed 30.3\% annual investment growth in the real estate. The HP is characterized by high economic growth, rapid urbanization which generated the higher affordability demand for houses. There are several forces of this rising trend in the housing market and MR is one of them (Wei and Zhang, 2011). According to the Ministry of Civil Affairs, the MR decreased in 2015-2017 with an average rate of $6.7 \%$, driven by the economic decision like housing and cost on raising a child.

The objective of the study is found on the fact that the housing sector plays a meaningful role, having witnessed a boom across China. The high HP resulted in the real estate bubble which can ultimately burst and damage China's economy. The process of capital accumulation along a regulated regime has attracted foreign investment in economic development. The commodification of housing has developed the investment item and provides revenues to the local governments. The reforms process started after 1978 has brought prosperity on the economic and social front. However, MR highlighted a downward trend and predicted the worse situation. The dramatic contributing factor is homeownership, which has a higher importance in the Chinese tradition since it is a predetermined condition to have a house before entering MR. This phenomenon has increased the competition for MR and has been intensified by the imbalance in the gender ratios across China (Wei et al., 2017). There are more than 34 million marriageable men than women in China, which may cause pressure on the real estate (Zhang et al., 2012). As indicated that China has the highest saving rate and household saving grows to over $50 \%$. The absence of investment outlets other than banks, which give a low rate of returns and high inflation, has directed the savings to the real estate (Zhang et al., 2012). Moreover, the strict capital control of the central government and lack of investment opportunities for the household in the global financial market has pushed toward the real estate. The household considers it as a useful way to tackle the impact of inflation. The extraordinary economic growth in the last decades has raised the expectations that China's economy will grow, and that the

\footnotetext{
${ }^{5}$ These policies intended to enhance the function of the real estate market and raised the down payment for buying second house.
} 
Do House Prices and Marriages Move Together in China?

household income will increase. Therefore, real estate maintains a significant position in the overall development and MR is the basis of society.

This paper enriches the current literature in different forms. First, China has experienced societal changes especially since 1978 and policies changes such as privatization and public sector enterprises have altered the process of individuals' marital behavior. Therefore, this study provides an insight into the economic perspective of HP on the MR at the regional level. Second, the study discloses that HP varies across regions and that MR can influence the HP heterogeneously. The results explore that HP and MR have a relationship in a fewer number of the Eastern and Central provinces due to tight land supply and economic development as well as that MR does not constitute a substantial portion of the housing demand which can control the movement of the HP and vice versa. These regions have the highest household income, housing affordability and population density, which resulted in new housing demand. Whereas in the Western region the HP and MR have a significant relationship which highlights the importance of MR. The Western region is less developed, and land is easily available which is evident in the low HP as compared the other regions and the cultural requirements can attribute to the causality between the HP and MR. Our results conclude that HP and MR have bidirectional causality for the Western regions as well as for Beijing and Henan in the Eastern and Central region, respectively. Likewise, HP has an effect on the MR in Tianjin in the Eastern region. While the MR is leading HP in Jilin in the Northeastern region. The results do not support the duration model, stating that HP increase leads to a decrease in MR. The rising HP will cause MR, which will further impact the sex-ratio balance, severe the marriage competition and wealth inequality of the household. The government should formulate policies in order to balance both and to rationalize the housing segment and dishearten irregular HP.

The paper structure continues with the second section, consisting of a literature review, followed by the third section which elucidates the methodology. In the fourth section we debate on the duration model, followed by the fifth section which outlines the data and evaluates the results. The last section of this study is conclusion.

\section{Literature Review}

Previous studies include several studies about the relationship between HP and MR. Martínez-Granado and Ruiz-Castillo (2002) conclude that MR decision relies on HP. Lauster (2006) reports that MR is increased due to greater access to housing. Martins and Villanueva (2009) present that home mortgage cost has decreased the ratio of MR. Mulder and Billari (2010) find that countries with low housing ownership and lack of access to mortgages have a negative impact on MR. Farnham et al. (2011) report that a

DOI: $10.24818 / 18423264 / 53.4 .19 .04$ 
decrease in HP has a significant influence on MR. Hui et al. (2012) suggest that an increase in HP leads to postponement of MR. Mulder (2013) explores how homeownership is a vital factor in MR formation. Farzanegan and Fereidouni (2014) study the link between HP and MR in Iran and their findings detect that HP has a negative impact on MR. Fereidouni (2016) analyzes the HP and dissolution of marriages and find that increase in the HP has decreased MR. Assaad et al. (2017) inspect the real estate market association with MR and results show that HP has a positive impact on MR.

There are some studies about the association between HP and MR in China. Wei and Zhang (2011) report that gender imbalance ratios increase marriage competition and large saving is used by the groom's family to buy a house at the time of MR. Wei et al. (2012) notice that housing is perceived as a status symbol supporting the motivation of the partner for MR. Zhang et al. (2012) suggest that MR has minimal impact on HP. Li and Chand (2013) state that MR contributes a significant part in the housing demand and without housing, marriage is considered incomplete. Li et al. (2014) analyze the property prices and housing affordability and reveal that homeownership is prerequisite of MR. Yu and Xie (2015) detect that higher HP is associated with early entry into MR and vice versa. Li and Song (2016) reveal that Chinese culture has pushed the HP as owning a house is condition majority of MR. Wei et al. (2017) argue that MR motivates people to pursue ownership of expensive houses. Wrenn et al. (2018) notice that MR has declined due to an increase in HP.

Previous literature has presented that the relationship between the HP and MR has several limitations. First, almost all of these studies - Zhang et al. (2012); Fereidouni (2016); Assaad et al. (2017) and Wrenn et al. (2018) - have explored the nexus between HP and MR on the country level and has ignored the regional dimension which may vary across the different regions. Thus, considering the crosssection dependency and heterogeneity is an important element in regional housing and MR study and the absence of such characteristics will lead to inappropriate results. Second, studies have reviewed this association considering the reverse feedback. The work of Farzanegan and Fereidouni (2014) and Fereidouni (2016) analyze the relationship running from HP to MR and have ignored the causality from the MR to HP. However, the reverse impact in the context of China is extremely crucial because housing is one of the prerequisite conditions of MR and a status symbol. Therefore, MR plays an imperative contribution to the housing market and analyzing the two-way relationship will give clear information about the housing market and MR. Third, some studies are based on survey methods which may be limited to a specific region, examples being studies such as Lauster (2006); Martins and Villanueva (2009); Zhang et al. (2012) and Wrenn et al. (2018). The results lack the power to generalize and be representative for the whole population. Last, most of the studies have utilized 
Do House Prices and Marriages Move Together in China?

conventional methods to evaluate the relationship. Papers such as those of Farnham et al. (2011); Hui et al. (2012); Farzanegan and Fereidouni (2014) and Fereidouni (2016) have used the generalized method of moments (GMM), autoregressive distributed lag models (ARDL) and autoregressive distributed lag vector autoregression (VAR). These cannot detect the cross-sectional relationship between variables and lack the power to notice time variation. Moreover, such techniques may have a prerequisite of the pretesting for stationarity and cointegration which may lead to biased results.

\section{The Duration Model}

We evaluate the relationship between the HP and MR by mean of the Duration model proposed by Weiss (1977) The response of the high HP can be negative under certain condition and the household faces a tradeoff between MR and consumption. It indicates that the benefits of MR for both man and women is greater than to be single, thus attracting individuals to enter the marriage relationship. There are several expenses required while getting MR including dowry and housing (Wrenn et al., 2018). The most important determinant is the housing ownership which can prevail on the MR decision. However, the rising HP may be one of the barriers in the delayed and falling rate of MR. Individuals maximize utility by having a budget constraint and deciding to allocate their income on consumption and MR. Similarly, MR is supposed to be a normal good and households maximize their utility by deciding on MR and consumption under the budget constraints. Thus, the maximization problem for an individual is as follows:

$$
\begin{gathered}
\max U(M R, C) \\
\text { s.t. } P_{M R}+P_{H P} H(M R)+C=I
\end{gathered}
$$

where $\mathrm{C}$ is the MR numeraire goods and $\mathrm{H}$ represents the housing. The price of numeraire goods is normalized to $1 . P_{M R}$ and $P_{H P}$ are prices for marriage and housing. However, inclusion in the budget constraints housing important is for the MR. It is assumed that utility is increasing in consumption and MR: $U_{M R}>0$ and $U_{C}>0$. Moreover, the marginal utility is across marriage and consumption: $U_{M R C}>0$. The $\frac{d H P}{d M R}$ is positive as HP is an increasing function for MR. The first order conditions are;

$$
\begin{aligned}
& U_{M R}\left(M R^{*}, C^{*}\right)+\lambda^{*}\left(-P_{M R}-P_{H P} \frac{d H P}{d M R}\right)=0 \\
& U_{C}\left(M R^{*}, C^{*}\right)-\lambda^{*}=0
\end{aligned}
$$


where $\lambda$ is the Lagrange multiplier indicates the marginal utility of income. $\left(M R^{*}, C^{*}, \lambda^{*}\right)$ is the solution given the maximization problem. From Equation (3), we have $\frac{U_{M R}}{\lambda}=P_{M R}+P_{H P} \frac{d H P}{d M R}$ which is the shadow price of MR. Since, $\frac{d H P}{d M R}>0$ the shadow price of the MR increases as the house prices. We obtain the MR statistics regarding to HP as

$$
\frac{d M R}{d P H}=\frac{\left[-\lambda \frac{d H P}{d M R}+H\left(M R^{*}\right) *\left(U_{M R C}\left(p_{M R}+P_{P H} \frac{d H P}{d M R}\right) U_{C C}\right)\right]}{\left[-U_{M R}+U_{M R C}\left(P_{M R}+P_{P H} \frac{d H P}{d M R}\right]\right.}
$$

where $U_{M R C}>0, U_{M R}<0, U_{C C}<0, \lambda^{*}>0$. HP has a negative impact on MR as $\frac{d M R}{d P H}<0$. However, the compensated substitution impact $\frac{d H P}{d M R}$ reveals that variation in the housing demand changes the MR. The increase in the HP will cause to reduce the demand for housing which may lead to a decrease in the MR. The second term should capture the income effect $H P\left(M R^{*}\right) * P_{M R}$, shows the total expenditure on housing can be found in the second term. The budget limitation will arise when the HP increases. As we have assumed that MR is the normal good and soaring HP will reduce the housing demand caused by the income and compensated substitution effect. Hence it is determined that higher HP will lead to a decline in MR.

\section{Panel causality test}

The suitable causality method is extremely important when the provinces have cross-sectional dependency (CD) and heterogeneity. Thus, Kónya (2006), endorsed the appropriate technique of the bootstrap panel, which measures the interconnection based on the Seemingly Unrelated Regression (SUR) estimation. This technique has three advantages. First, it reviews the causal association between each panel member separately as it assumes heterogeneity which offers further evidence related the specific group members. Second, it does not need to test the unit root and cointegration test, as different such tests may cause results to be contradicting (Kónya, 2004). Third, it can find whether there is unidirectional, bidirectional or no Granger causality of as many as panel member. The bootstrap critical value about the provinces is valuable because they are independent of the unit root and cointegration characteristics. The number of provinces which have the Granger causality is also revealed by imposing provinces-specific restrictions. The process is specified in the following form: 
Do House Prices and Marriages Move Together in China?

$$
\begin{aligned}
& M R_{1, t}=\chi_{1,1}+\sum_{i=1}^{l g_{1}} \varphi_{1,1, i} M R_{1, t-i}+\sum_{i=1}^{l r_{1}} \psi_{1,1, i} H P_{1, t-i}+\sum_{i=1}^{l s_{1}} \xi_{1,1, i} G D P_{1, t-i}+\varepsilon_{1,1, t} \\
& M R_{2, t}=\chi_{1,2}+\sum_{i=1}^{l g_{1}} \varphi_{1,2, i} M R_{2, t-i}+\sum_{i=1}^{l r_{1}} \psi_{1,2, i} H P_{2, t-i}+\sum_{i=1}^{l s_{1}} \xi_{1,2, i} G D P_{2, t-i}+\varepsilon_{1,2, t}
\end{aligned}
$$

$$
\begin{aligned}
& M R_{N, t}=\chi_{1, N}+\sum_{i=1}^{l \mathrm{~g}_{1}} \varphi_{1, N, i} M R_{N, t-i}+\sum_{i=1}^{l r_{1}} \psi_{1, N, i} H P_{N, t-i}+\sum_{i=1}^{l s_{1}} \xi_{N, 1, i} G D P_{N, t-i}+\varepsilon_{1, N, t} \\
& H P_{1, t}=\chi_{1,1}+\sum_{i=1}^{l \mathrm{~g}_{2}} \varphi_{2,1, i} H P_{1, t-i}+\sum_{i=1}^{l r_{2}} \psi_{2,1, i} M R_{1, t-i}+\sum_{i=1}^{l s_{2}} \xi_{2,1, i} G D P_{1, t-i}+\varepsilon_{2,1, t} \\
& H P_{2, t}=\chi_{1,2}+\sum_{i=1}^{l \mathrm{~g}_{2}} \varphi_{2,2, i} H P_{2, t-i}+\sum_{i=1}^{l r_{2}} \psi_{2,2, i} M R_{2, t-i}+\sum_{i=1}^{l s_{2}} \xi_{2,2, i} G D P_{2, t-i}+\varepsilon_{2,2, t}
\end{aligned}
$$

$$
H P_{N, t}=\chi_{1, N}+\sum_{i=1}^{l \mathrm{~g}_{2}} \varphi_{2, N, i} H P_{N, t-i}+\sum_{i=1}^{l r_{2}} \psi_{2, N, i} M R_{N, t-i}+\sum_{i=1}^{l s_{2}} \xi_{2, N, i} G D P_{1, t-i}+\varepsilon_{2, N, t}
$$

where $l$ is the lag length. Gross domestic product (GDP) represents the control variable. The hypothesis of the Granger causality test can be found in the provinces in the four possible form: (i) The uni-directional Granger causality will exist from HP to MR if not all $\psi_{1,1, i}$ are zero but all $\varphi_{2, i}$ are zero. (ii) There will be unidirectional causality running from MR to HP if all $\psi_{1,1, i}$ are zero but not all $\varphi_{2, i}$ are zero. (iii) The MR and HP will have a bi-directional Granger causality when both $\psi_{1,1, i}$ nor $\varphi_{2, i}$ are not zero. (iv) The MR and HP will have no causal link when all $\psi_{1,1, i}$ and $\varphi_{2, i}$ all are zero. The selection of the lag structure is vital because it can influence the results. Especially in the large panel having the varying lag structure can cause the computational burden. The problem is sorted out by Kónya (2006) who uses maximum lag to vary through variables. We assume from 1 to 4 lags to calculate the system for each possible pair of $l_{\mathrm{g} 1}, l r_{1}, l_{g 2}$, and $l r_{2}$ and then select the group that minimizes the Bayesian information criterion. 


\section{Data and Empirical results}

This study analyses the nexus between the HP and MR at the provincial level of China by means of bootstrap Granger causality test. Our sample includes 30 provinces between 1998 to 2018. The housing market witnessed an unprecedented boom since the beginning of the housing reforms and private housing system was started in 1998, when the welfare system was sidelined. The real estate investment became one of the most attractive sectors and an important contributor in the GDP, provided huge revenues to local governments. The spiraling HP was basically fueled by government policies. However, the MR declined around 1998 consecutively for six years eroded by marketization, economic reforms and influence of the Western culture (Yu and Xie, 2015). Moreover, the reforms process has introduced the one-child policy which has caused the imbalance of sex ratios and resulted in an oversupply of marriageable men and created severe competition for the MR (Wrenn et al., 2018). It is predicted that this gender inequality will further increase and there will be more than 30 million men who will be unable to get married. Consequently, the government abolished the one-child policy in 2015 to alleviate the gender imbalance which can be more serious. The HP is equivalent to the average selling price of the commercial house divided by sales area (Su et al., 2018). The MR is the rate of registered marriage per 10000 population for each province (Farzanegan and Fereidouni, 2014), obtained from the China Statistics Yearbook available from the National Bureau of Statistics of China (NBSC). Both HP and MR are corrected for heteroscedasticity by converting into natural logarithms. The geographical location, economic conditions, and regional distinctions differentiate these provinces into Eastern, Central and Western and Northeastern regions, respectively (Zhang et al., 2012). Table 1 illustrates the descriptive statistics of HP and MR about four regions and describe regional differences. The mean value of HP of the Eastern regions is highest followed by the Northeastern and Western regions respectively. Likewise, the highest mean value of the MR is observed in the Central region, followed by the Eastern and Northeastern regions, respectively. It finds that the level of development in the Eastern regions is greater with higher housing affordability, dense populations and the largest destination of the migration from Central and Western regions. It suggests that compared to the other regions, Eastern province's housing competition is higher as the availability of land supply and credit are tighter. However, the HP shows greater volatility in the Eastern provinces followed by Central and Northeastern region. As the Eastern region is more diverse than the other three regions in term of industries, economic development, education level, housing affordability, gender imbalance, and women work participation. It shows that MR is the most unpredictable in the Central region which faces the highest gender imbalance and has increased the MR expense and without new housing, the probability of marriage is very low. As compared to the 
Do House Prices and Marriages Move Together in China?

Eastern region, the other three regions are more inclined to tradition and homeownership has a higher probability of MR. All these factors make the Eastern region more competitive, unstable and vulnerable to the higher HP and lower MR. Moreover, the MR has positive skewness and HP has a negative one. Lastly, as per Jarque-Bera test all series are normally distributed.

Table 1. Descriptive statistics of HPs and MR

\begin{tabular}{lcccccccc}
\hline & \multicolumn{2}{c}{ Eastern } & \multicolumn{2}{c}{ Central } & \multicolumn{2}{c}{ Western } & \multicolumn{2}{c}{ Northeastern } \\
\hline & HP & MR & HP & MR & HP & MR & HP & MR \\
\hline Mean & 8.498 & 13.51 & 7.703 & 13.822 & 7.712 & 13.120 & 7.793 & 13.138 \\
Std. Dev & 0.638 & 0.179 & 0.640 & 0.280 & 0.541 & 0.199 & 0.606 & 0.153 \\
Skewness & -0.032 & 0.036 & 0.077 & 0.947 & -0.011 & 0.078 & -0.008 & 0.052 \\
Kurtosis & 1.462 & 1.603 & 1.643 & 3.794 & 1.547 & 1,443 & 1.513 & 1.580 \\
Jarque-Bera & 1.874 & 1.548 & 1.475 & 3.342 & 1.670 & 1.938 & 1.748 & 1.604 \\
\hline \multicolumn{2}{l}{ Note: HP denotes housing prices, MR signifies marriages } & \multicolumn{4}{l}{}
\end{tabular}

Note: HP denotes housing prices, MR signifies marriages

The beginning of the market-oriented reforms considered economic decentralization and fiscal reform boosts the HP. Since 1979, China has noticed numerous housing market cycles. Numerous measures have been taken to change the pre-reform housing to the market-driven and led to the emergence of the private housing system ( $\mathrm{Yu}$ and Xie, 2015). The share of the private housing supply increase from 13\% in 1986 to $33 \%$ in 1996. During 1998-2000, the market passed through effects of the Asian financial crisis and the central government has tight control over the land. The crisis decreased export and foreign investment which in turn has made the housing market downward. There is no notable rise in MR and even recorded the lowest registration rate during this time period. However, the most important period is 2003-2013 when the Chinese housing market recorded an extraordinarily high HP. It is driven by the end of the public housing system, investment returns, and accelerated rural-urban migration and it has pushed the demand for housing. While an average increase of $13.1 \%$ in HP was observed in some cities such as Shenzhen, Beijing and Shanghai (Wrenn et al., 2018). The period is characterized by greater economic growth, rapid urbanization and highest rate of return in real estate investment which has increased the HP. This conducive environment of the investment, as well as the social element like the MR, has generated the housing demand. Housing ownership is considered the important requirement in Chinese culture in most of MR which pushes the HP up ( $\mathrm{Li}$ and Song, 2016). It is evident that competitiveness for the MR has increased during the period and the provinces of Hebei, Jiangsu, Shandong, Henan and Guangdong has reported the highest number of MR. Similarly, the HP has displayed the boom in 2007 mainly driven by the capital flight from the manufacturing industries to the real estate investment sectors.

DOI: 10.24818/18423264/53.4.19.04 
The central government tightened the land supply and housing market to control the heated HP in 2008 which has failed to create a substantial impact on the rising trend. However, the pace of the soaring HP has slowed down due to the financial crisis in 2008. The government extended the stimuli package and lowered the interest rate to minimize the effects of the crisis. Furthermore, the minimum capital requirement for housing purchase was reduced for low-income families and 33 billion yuan was invested in the "social security housing6" to stabilize the housing industry. The investment in real estate increased by $32 \%$, which has pushed HP in all the major cities. On the other hand, there is a persistent increase in the MR during the period. The latest housing boom was observed around 2015 when the economic growth has slowed down from $10 \%$ to $7 \%$, still the HP has experienced an upward trend of an average of $10 \%$. This increase is more vigorous in big cities like Beijing, Shanghai, and Shenzhen. However, the MR has shown a declining trend during 2014-2017 as a lower number of MR were registered, due to the sex-imbalance ratio which resulted in far more marriageable men than women. The homeownership of young people has comparative advantages of getting married which have pushed the housing market up. The basic motive behind the study is the booming trend in the HP, their relative shares in the GDP, source of revenues for the local government and attractive sector of investment. Basically, driven by the economic growth, store of the value, the rapid process of the urbanization, the rising household income and the cultural requirement have made the discussion very important about the HP and MR in China.

The panel bootstrap approach requires the selection of a suitable estimator. Both the CD and LM test are used for this purpose to choose the appropriate technique. These tests are valuable due to the higher economic integration of the Chinese provinces. Thus, the first phase of this study is to conduct the cross-sectional and slope homogeneity test across these provinces. It is carried out using three different kinds of test ( $L M, C D, C D_{l m}$ ) and results are demonstrated in Table 2. It explores that no $C D$ hypothesis is rejected at a $1 \%$ significance level, validate that provinces have a spillover effect. The results confirmed the suitability of the SUR technique in the panel causality technique. The finding of the slope homogeneity test recommends that shock spreads among provinces and will vary across the regions. We conclude from the outcome of both tests that panel bootstrap Granger causality is a fitting technique to analyze the causality relationship between the HP and MR.

\footnotetext{
${ }^{6}$ The special housing program started by the government with aim of provision of housing to low income families.
} 
Do House Prices and Marriages Move Together in China?

Table 2: Cross-sectional dependence and homogeneity tests.

\begin{tabular}{llcc}
\hline & Test & HP & MR \\
\hline Breusch and Pagan (1980) & $L M$ & $1174.721^{* * * *}$ & $1613.972^{* * * *}$ \\
Pesaran (2004) & $C D$ & $23.273^{* * * *}$ & $37.676^{* * *}$ \\
Pesaran (2004) & $C D_{l m}$ & $21.819^{* * *}$ & $25.894^{* * *}$ \\
Swamy (1970) & $\tilde{S}$ & $255.486^{* * *}$ & $436.343^{* * *}$ \\
Pesaran and Yamagata & $\tilde{\Delta}$ & $66.410^{* * *}$ & $124.229^{* * *}$ \\
Pesaran and Yamagata & $\tilde{\Delta}$ & $40.271^{\text {**** }}$ & $56.550^{* * *}$ \\
$(2008)$ & & & \\
\hline
\end{tabular}

Note: $* * *$ indicates significance at the 0.01

The results about the causality between the HP and MR are declared in Table 3. It displays that HP has no significant impact on the MR except Beijing and Tianjin in the Eastern region and majority of the provinces except Henan in the Central and in all provinces of the Northeastern region. Findings suggest that HP does not play vital input in the MR in these regions. While the HP does Granger cause the MR in most of the Western provinces except Guangxi, Ningxia, and Xinjiang. This is similar to results of Assaad et al. (2017), that HP eases the MR. The Eastern region achieved greater economic development, highly urbanized with dense population, higher education level, and greater purchasing power. This is the migration destination for the other three regions, fully integrated with the global economy and greater openness. However, the HP is leading the MR in Beijing and Tianjin, has higher household income and population density which may cause housing problems and put pressure on MR. The most extreme HP have been observed due to the breakdown of the state housing system followed by the increase in the HP. It indicates a nexus between the economic status and the MR formation among the urban residents and has pushed them to have higher savings for housing. The shortage of land supply has slowed down the construction of new houses in Beijing, which may exert pressure on the HP. The rising $\mathrm{HP}$ has a socioeconomic impact and is getting greater attention. Especially in the case of young married couples in Beijing, they will have to save their full income to purchase a house in 12 years.

The HP does not Granger cause the MR in the remaining provinces of the Eastern region due to the level of development, education and the global phenomenon of the falling MR. The greater participation of women in the workforce may also have significantly reduced the pressure on MR and housing. Similarly, real estate is driven by investment motives instead of social factors. The higher rate of return in the real estate because of strict regulation in the financial market has attracted investors towards real estate which pushed up the HP. MR does not make a substantial portion

DOI: 10.24818/18423264/53.4.19.04 
of the housing demand and has no significant contribution to the HP. These provinces belong to first and second-tier cities, which have higher disposable income, housing affordability, and foreign investors are potential speculators in the local market which dominated the HP. Likewise, the greater population density and moderate sex-ratio imbalances put no pressure on the nexus between the HP and MR (Wrenn et al., 2018). Results detect that HP do Granger cause the MR in the Central region. It is an agricultural and populated province, the origin of migrant to the first-tier provinces $(\mathrm{Li}$ et al., 2014). Henan is one of the provinces where extravagant spending has incurred on MR. As compared to the national level, the average income is lower, and some people borrow to get married. Then, the government cracked down and has set a restriction on wedding expenses which includes no housing and car as a gift. However, the remaining Central and the Northeastern regions are relatively less cohesive with economy and agricultural as imperative segments. The housing market is not fully developed in these third and fourth-tier cities and is relatively moderate in the two regions. The low housing demand makes the investment environment less attractive (Su et al., 2018) and has no effect on MR. Similarly, in these cities the land supply growth is continued with strong investment to residential housing of about $25 \%$ of the total fixed investment.

Results for the Western region presents that HP has a positive impact on MR in most of the provinces which can be attributed to the relaxed land supply and HP are relatively lower than in other regions. It indicates that growing HP will lead to an increase in MR ( $\mathrm{Li}, 2018)$. These cities having low HP and couples will not wait long to get married and HP is not an obstacle in MR (Yu and Xie, 2015). Further, the level of development and purchasing power of the people in the Western region is lowest as compared to the other two regions and make the real estate less attractive and competitive for the investors. The housing market is in its initial phases which further need to be exploited. While, Guangxi, Ningxia, and Xinjiang the HP have no impact on MR because these provinces have a unique tradition and remote autonomous ethnicity position (Jia and Yeung, 2014). The ethnic minority group has its distinctive tradition and is different from the mainstream culture which is less influenced by MR. People tend to get married at an early age and with greater rate with no effect from the HP.

Table 3. Test for Granger causality effects of HP on MR

\begin{tabular}{llllll}
\hline & \multicolumn{5}{c}{ Bootstrap critical value } \\
\cline { 2 - 6 } & $\mathrm{C}$ & Wald test & $1 \%$ & $5 \%$ & $10 \%$ \\
\hline Eastern Region & & & & & \\
Beijing & 0.202 & $16.429^{*}$ & 37.262 & 20.404 & 15.539 \\
Fujian & -0.949 & 0.146 & 37.631 & 30.482 & 20.245 \\
\hline
\end{tabular}


Do House Prices and Marriages Move Together in China?

\begin{tabular}{|c|c|c|c|c|c|}
\hline Guangdong & 0.102 & 5.980 & 31.887 & 22.453 & 17.963 \\
\hline Hainan & 0.08 & 1.299 & 28.483 & 15.966 & 11.802 \\
\hline Hebei & -0.033 & 1.887 & 20.272 & 10.778 & 7.381 \\
\hline Jiangsu & 0.077 & 9.447 & 56.576 & 20.425 & 16.593 \\
\hline Shandong & -0.250 & 0.102 & 41.294 & 14.747 & 11.513 \\
\hline Shanghai & 0.055 & 2.677 & 25.970 & 14.198 & 10.116 \\
\hline Tianjin & 0.298 & $48.014^{* * *}$ & 36.722 & 24.082 & 15.235 \\
\hline Zhejiang & 0.019 & 1.394 & 25.145 & 16.664 & 10.797 \\
\hline \multicolumn{6}{|l|}{ Central region } \\
\hline Anhui & 0.018 & 0.266 & 10.892 & 6.957 & 5.396 \\
\hline Henan & 0.129 & $11.764^{*}$ & 59.617 & 19.635 & 10.933 \\
\hline Hunan & -0.16 & 0.133 & 28.893 & 16.320 & 13.779 \\
\hline Jiangxi & 0.274 & 0.248 & 36.173 & 16.262 & 11.039 \\
\hline Shanxi & 0.015 & 0.270 & 75.658 & 22.940 & 15.84 \\
\hline Hubei & 0.016 & 0.354 & 38.367 & 25.479 & 15.951 \\
\hline \multicolumn{6}{|l|}{ Western region } \\
\hline Chongqing & 0.114 & $20.438^{* * * *}$ & 17.852 & 9.545 & 8.425 \\
\hline Gansu & 0.116 & $15.831^{*}$ & 25.869 & 17.643 & 11.990 \\
\hline Guangxi & -0.019 & 0.341 & 30.454 & 20.160 & 14.329 \\
\hline Guizhou & 0.137 & $43.066^{* * *}$ & 25.166 & 14.964 & 13.168 \\
\hline Inner Mongolia & 0.113 & $13.378^{*}$ & 18.275 & 10.805 & 8.108 \\
\hline Qinghai & 0.147 & $13.777^{*}$ & 37.362 & 15.936 & 10.336 \\
\hline Shaanxi & 0.135 & $11.830^{*}$ & 17.733 & 12.797 & 10.239 \\
\hline Sichuan & 0.144 & $58.538^{* * * *}$ & 27.434 & 19.335 & 12.447 \\
\hline Yunnan & 0.196 & $33.509^{* * *}$ & 31.622 & 22.800 & 13.000 \\
\hline Ningxia & 0.201 & 1.323 & 6.886 & 4.625 & 3.234 \\
\hline Xinjiang & -0.026 & 0.397 & 32.807 & 20.124 & 9.593 \\
\hline \multicolumn{6}{|c|}{ Northeastern region } \\
\hline Liaoning & 0.079 & 5.658 & 27.421 & 18.527 & 10.76 \\
\hline Heilongjiang & 0.087 & 4.992 & 27.365 & 18.580 & 7.768 \\
\hline Jilin & 0.016 & 0.549 & 17.744 & 12.188 & 6.606 \\
\hline \multicolumn{6}{|c|}{$\begin{array}{l}\text { Note: } * * *, * *, * \text { indicate significance at the } 0.01,0.05 \text { and } 0.1 \text { level, respectively. Bootstrap } \\
\text { critical values are obtained from } 10,000 \text { replications }\end{array}$} \\
\hline \multicolumn{6}{|c|}{$\begin{array}{l}\text { Table } 4 \text { illustrates the results of the causality running from MR to HP in all } \\
\text { four regions. Results show that MR is not leading the HP in the Eastern region } \\
\text { excluding Beijing, the Central region except Henan and Northeastern region except } \\
\text { Jilin. However, MR does Granger cause in almost all the provinces in the Western } \\
\text { region except Guangxi, Ningxia, and Xinjiang. Findings reveal that MR does not } \\
\text { dominate the HP. The majority of the provinces in the Eastern region except for } \\
\text { Beijing MR does not Granger cause the HP because of higher development and } \\
\text { affordability. Beijing has the advantage of educational resources, healthcare } \\
\text { infrastructure and employment opportunities which have attracted migrants from the }\end{array}$} \\
\hline
\end{tabular}


Ruzhi Xu, Khalid Khan, Nicoleta Claudia Moldovan, Anda Iosif

Central and Western regions (Li et al., 2014). The higher disposable income, gender imbalance, and greater divorce rate have increased the struggle for MR. The homeownership gives an advantage to men and perceived security to attract women. There is no relationship between MR and HP in the remaining provinces of the Eastern region. Most of these provinces have a higher level of economic integration, an openness which relatively relieves traditional pressure in the MR formations (Li et al., 2014). The average MR age and education level is getting higher which has a significant role in MR falling. The increasing tendency in female education, the boom of the social media and the desire of the career and self-identity has diminished the rate of MR. The growing divorce rate in these cities can also discourage the people to enter in the MR which makes no considerable demand for the housing.

Table 4. Test for Granger causality effects of MR on HP

\begin{tabular}{llllll}
\hline & \multicolumn{5}{c}{ Bootstrap critical value } \\
\cline { 2 - 6 } & $\mathrm{C}$ & Wald test & $1 \%$ & $5 \%$ & $10 \%$ \\
\hline Eastern Region & & & & & \\
Beijing & 0.678 & $43.360^{* * *}$ & 25.792 & 23.888 & 15.413 \\
Fujian & -0.949 & 0.146 & 31.291 & 18.073 & 15.047 \\
Guangdong & 0.102 & 5.980 & 48.894 & 31.833 & 13.454 \\
Hainan & 0.085 & 1.2995 & 25.093 & 17.629 & 10.869 \\
Hebei & 0.101 & 1.335 & 37.480 & 21.073 & 18.006 \\
Jiangsu & -0.169 & 1.790 & 35.251 & 26.203 & 18.019 \\
Shandong & -0.250 & 0.102 & 23.964 & 16.056 & 8.935 \\
Shanghai & 0.190 & 1.103 & 46.112 & 21.035 & 14.859 \\
Tianjin & 0.216 & 2.706 & 34.505 & 19.373 & 15.805 \\
Zhejiang & 0.019 & 1.394 & 15.054 & 9.87515 & 7.318 \\
Central region & & & & & \\
Anhui & 0.018 & 0.266 & 13.961 & 7.31092 & 4.613 \\
Henan & 0.129 & $11.764^{*}$ & 14.640 & 12.251 & 11.270 \\
Hunan & -0.016 & 0.331 & 20.188 & 13.964 & 9.393 \\
Jiangxi & 0.274 & 0.246 & 12.902 & 11.140 & 9.275 \\
Shanxi & 2.058 & 16.296 & 53.358 & 21.686 & 16.759 \\
Hubei & 0.016 & 0.354 & 34.450 & 23.092 & 12.932 \\
Western region & & & & & \\
Chongqing & 0.114 & $20.438^{* *}$ & 25.953 & 11.100 & 8.648 \\
Gansu & 0.116 & $15.831^{* *}$ & 23.409 & 14.009 & 10.765 \\
Guangxi & -0.019 & 0.341 & 31.452 & 19.111 & 14.397 \\
Guizhou & 0.137 & $43.066^{* * *}$ & 26.172 & 20.018 & 12.871 \\
Inner Mongolia & -0.749 & 11.369 & 56.008 & 28.171 & 18.245 \\
Qinghai & 0.147 & $13.777^{*}$ & 34.232 & 17.501 & 11.505 \\
Shaanxi & 0.135 & $11.830^{* *}$ & 32.802 & 14.260 & 11.956 \\
Sichuan & 0.144 & $68.53^{* * *}$ & 28.947 & 20.572 & 13.854 \\
\hline & & & & & \\
& & & & &
\end{tabular}


Do House Prices and Marriages Move Together in China?

\begin{tabular}{llllll}
\hline & \multicolumn{5}{l}{} \\
\hline Yunnan & 0.196 & $33.509^{* * *}$ & 23.188 & 16.695 & 13.736 \\
Ningxia & 0.201 & 1.323 & 9.394 & 7.135 & 5.371 \\
Xinjiang & -0.026 & 0.397 & 35.002 & 13.284 & 8.590 \\
Northeastern & & & & & \\
Liaoning & 0.164 & 3.832 & 47.660 & 30.820 & 14.774 \\
Heilongiiang & 0.413 & 4.245 & 37.969 & 20.175 & 12.553 \\
Jilin & 1.317 & $20.130^{* * *}$ & 19.587 & 14.316 & 10.057 \\
\hline
\end{tabular}

Note: $* * *, * *, *$ indicate significance at the $0.01,0.05$ and 0.1 level, respectively. Bootstrap

critical values are obtained from 10,000 replications

The causality running from MR to HP has been detected in Henan and Jilin in Central and Northeastern regions, respectively. The reform process is underway by adjusting the industrial structure and macroeconomic policy to exploit the economic potential (Su et al., 2018). Similarly, Jilin has the lowest fertility and highest divorce rate in China. These factors may cause a gap between the marriageable men and women and increase the competition for MR which translated into the higher demands for the housing. Further, these two provinces are considered to be relatively inclined to tradition which gives value to the universal institution of MR. Higher competition for MR causes an increase in demand for housing and ultimately exerts pressure on the HP. However, MR has no impact on the HP in the remaining provinces because low housing affordability mainly attributed to the higher migration to the Eastern region which has relaxed the pressure on the HP. These provinces have the highest number of vacancy ratios which is the result of the desire of the higher investment returns. The household income and population are low which do not further create housing demand (Li et al., 2014).

We find that most of the Western provinces have Granger caused the HP. The gender imbalance ratio is low in the region which has less impact on the MR competition. These are more isolated and follow the tradition where homeownership is the prerequisite for MR. The housing market is not developed, and the supply of the house is relaxed which has not pushed the HP very high. In cities with lower HP, people are getting married according to tradition ( $\mathrm{Yu}$ and Xie, 2015). However, the ethnic minority provinces of Guangxi, Ningxia, Xinjiang follow their own customs and get married at an early age. The study has specific policy recommendations. First, results indicate that Eastern and Central regions have no causal link between the HP and MR. The rising HP is upset by the higher household's income due to unprecedented economic growth in past decades. MR declined mainly due to higher demographic transition and economic prosperity. The declining pattern in MR may further aggravate gender balance in China and can increase the demand for housing to enhance the getting married. Therefore, the government should initiate policies like lower residential costs for couples and a less cumbersome registration process to

DOI: $10.24818 / 18423264 / 53.4 .19 .04$ 
attract people towards MR. Second, in the Western region, HP and MR are contributing components which show that the region is still not fully developed, having a low level of education. The booming HP can lead to wealth inequality and financial constraints. Thus, policies should be directed towards streamlining the housing sector and discouraging uneven HP. Last, there should be a social harmonization among households and a pledge to reduce demand for a house before MR which can mitigate the severe consequences of the HP and cause less damage to marriage. Additionally, there should be a rising awareness program to discourage the desire to have only sons and to abort daughters. This can help in mitigating the gender imbalance ratios and will provide more marriageable women in the highly competitive MR market of China. Our results detect that there is a bidirectional relationship between the HP and MR in Beijing and Henan in the Eastern and Central region respectively. Furthermore, HP influences MR in Tianjin in the Eastern provinces. Similarly, MR is leading the HP in the Northeastern region. While the result reveals the bidirectional connection between HP and MR in almost all the provinces in the Western region. It is concluded that HP has a positive impact on MR in almost onethird of the provinces, which is conflicting to the duration model, which states that rising HP have a negative impact on MR. The contrary finding may be due to the traditional norms in China which value homeownership as being a basic requirement for MR. Thus, policymakers should launch subsidized housing schemes and low-cost credits for couples which can attract people towards MR. Similarly, the government should concentrate on the level of education and equality of land development in all regions which can plug the unbalanced gap of HPs. Finally, the government should take steps on the social side to alleviate the high demand for housing for MR which results in the increases of HP. Therefore, authorities should introduce policies to educate people about gender equality and discourage them from demanding high dowry in the form of housing.

\section{Conclusion}

We study the causality between the HP and MR in the Chinese regions. Results suggest a bidirectional causal link between the HP and MR for the Western regions as well as for Beijing and Henan in the Eastern and Central region, respectively. However, unidirectional causality running from HP to MR exists in Tianjin in the Eastern region. Lastly, the MR leading the HP in the Northeastern region. Our results conclude that HP has a positive effect on MR which does not support the duration model, which states that a HP increase will lead to a decrease in MR. The HP affecting MR in several provinces is an indication that if the HP rises it may delay or reduce MR. It will disrupt society by making gender ratios more vulnerable and increasing marriage competition. The government should formulate

DOI: $10.24818 / 18423264 / 53.4 .19 .04$ 
Do House Prices and Marriages Move Together in China?

policies which would balance both the rationalize of the housing segment and dishearten irregular HP. Low-cost credit and government-sponsored housing facilities will encourage the people to MR. Similarly, policymakers should emphasize education and equal land development across all regions which will overcome unequal HPs. Last, there should be awareness to discourage housing as a dowry.

\section{REFERENCES}

[1] Assaad, R., Krafft, C., Rolando, D, J. (2017), The Role of Housing Markets in the Timing of Marriage in Egypt, Jordan, and Tunisia. Working Paper 1081;

[2] Aksoy, C. G. (2016), Short-term Effects of House Prices on Birth Rates. European Bank for Reconstruction and Development. Working Paper No. 192;

[3] Farnham, M., Schmidt, L., Sevak, P. (2011), House Prices and Martial Stability. American and Economic Review, 101(3), 615-619;

[4] Fereidouni, H. G. (2016), Housing Costs and Divorce Rate in MENA Countries. Topics in Middle Eastern and North African Economies, 18(1), 1-8;

[5] Farzanegan, R. M., Fereidouni, S, G. (2014), Marriage Crisis and Housing Costs: Empirical Evidence from Provinces of Iran. Working Paper No. 012014;

[6] Hui, E. C.M., Zheng, X., Hu, J. (2012), Housing Price, Elderly Dependency and Fertility Behavior. Habitat International, 36 (2), 304-311;

[7] Kónya, L. (2006), Exports and Growth: Granger Causality Analysis on OECD Countries with a Panel Data Approach. Economic Modelling, 23(6), 978-992;

[8] Li, J. (2018), Married to Property? Housing Price and Family Formation Revisited. International Journal of Home Economics, 11(1), 44-53;

[9] Li, J., Xu, Y., Chiang, Y. H. (2014), Property Prices and Housing Affordability in China: A Regional Comparison. Journal of comparative Asian development, 13(3), 405-435;

[10] Li, Q., Chand, S. (2013), Evidence of a Housing Bubble in Beijing. Academic Journal of Interdisciplinary Studies, 2(8), 627-634;

[11] Li, P., Song, S. (2016), What Pushes up China's Urban Housing Prices so High? The Chinese Economy, 49, 128-141;

[12] Li, T. (2018), The Impact of Rising Residential Land Cost on Divorce Rate. Open Journal of Social Sciences, 6(03), 168-182;

[13] Lauster, N. T. (2006), A Room of One's Own or Room Enough for Two? Access to Housing and New Household Formation in Sweden, 1968-1992. Population Research Policy Review, 25 (4), 329-351;

[14] Martins, N., Villanueva, E. (2009), Does the High Cost of Mortgage Debt Explain why Young Adults Live with their Parents? Journal of the European Economic Association, 7(5), 974-1010;

DOI: 10.24818/18423264/53.4.19.04 
Ruzhi Xu, Khalid Khan, Nicoleta Claudia Moldovan, Anda Iosif

[15] Martínez-Granado, M., Ruiz-Castillo, J. (2002), The Decisions of Spanish Youth: A Cross-section Study. Journal of Population Economics, 15 (2), 305330 ;

[16] Mulder, C. H., Billari, F. C. (2010), Homeownership Regimes and Low Fertility. Housing Studies, 25 (4), 527-541;

[17] Mulder, C. H. (2013), Family Dynamics and Housing: Conceptual Issues and Empirical Findings. Demographic Research, 29, 355-378;

[18] Su, C., Yin, X., Tao, R., Lobonț, O. R., Moldovan, N. C. (2018), Are There Significant Linkages between Two Series of Housing Prices, Money Supply and Short-Term International Capital? - Evidence from China. Digital Signal Processing, 83, 148-156;

[19] Wei, S. J., Zhang, X., Liu, Y. (2017), Homeownership as Status Competition: Some Theory and Evidence. Journal of Development Economics, 127, 169-186;

[20] Wei, S. J., Zhang, X. (2011), The Competitive Saving Motive: Evidence from Rising Sex Ratios and Savings Rates in China. Journal of Political Economy, 119(3), 511-564;

[21] Wei, S. J., Zhang, X., Liu, Y. (2012), Status Competition and Housing Prices (No. w18000). National Bureau of Economic Research;

[22] Weiss, Y. (1997), The Formation and Dissolution of Families: Why Marry? Who Marries Whom? And what Happens upon Divorce. Handbook of population and family economics, 1, 81-123;

[23] Wrenn, D, H., Yi, J., Zhan, B. (2018), House Prices and Marriage Entry in China. Regional Science and Urban Economics, 74, 118-130;

[24] Yu, J., Xie, Y. (2015), Changes in the Determinants of Marriage Entry in Postreform Urban China. Demography, 52(6), 1869-1892;

[25] Zhang, C., An, G., Yu, X. (2012), What Drives China's House Prices: Marriage or Money? China \& World Economy, 20(4), 19-36.

DOI: $10.24818 / 18423264 / 53.4 .19 .04$ 